This item was submitted to Loughborough's Research Repository by the author.

Items in Figshare are protected by copyright, with all rights reserved, unless otherwise indicated.

\title{
Improving heat ageing and thermal properties of silicone rubber using montmorillonite clay
}

\section{PLEASE CITE THE PUBLISHED VERSION}

http://dx.doi.org/10.1002/app.41061

\section{PUBLISHER}

(c) Wiley Periodicals Inc.

\section{VERSION}

AM (Accepted Manuscript)

\section{PUBLISHER STATEMENT}

This work is made available according to the conditions of the Creative Commons Attribution-NonCommercialNoDerivatives 4.0 International (CC BY-NC-ND 4.0) licence. Full details of this licence are available at: https://creativecommons.org/licenses/by-nc-nd/4.0/

\section{LICENCE}

CC BY-NC-ND 4.0

\section{REPOSITORY RECORD}

Ansarifar, Ali, Nik I. Nik Ismail, and Mo Song. 2017. "Improving Heat Ageing and Thermal Properties of Silicone Rubber Using Montmorillonite Clay”. figshare. https://hdl.handle.net/2134/23772. 


\title{
Improving heat ageing and thermal properties of silicone rubber using montmorillonite clay
}

\author{
Nik Intan Nik Ismail ${ }^{a, b}$, Ali Ansarifar ${ }^{a}$ and Mo Song ${ }^{a}$ \\ ${ }^{a}$ Materials Department, Loughborough University, Leicestershire LE11 3TU, UK \\ ${ }^{\mathrm{b}}$ Centres of Excellence, Advanced Processing and Product Technology, \\ Malaysian Rubber Board, 47000 Sungai Buloh, Selangor, Malaysia
}

\begin{abstract}
Heat ageing and thermal stability of a silicone rubber (SR) filled with montmorillonite clay (MMT) was investigated. Three types of rubber nanocomposites were prepared with highly exfoliated Cloisite 30B (SR/C30B), intercalated/exfoliated Cloisite $\mathrm{Na}^{+}$ (SR/Na $\left.{ }^{+} \mathrm{MMT}\right)$, and highly intercalated Cloisite 20A (SR/C20A). This study showed that the SR/C30B nanocomposite exhibited excellent heat resistance in comparison to the other two nanocomposites and neat SR as revealed by higher retention strength. The thermal stability of the rubber in air was strongly dependent on the clay morphology and increased in the following order: highly intercalated/exfoliated $\mathrm{SR} / \mathrm{Na}^{+} \mathrm{MMT}<$ highly intercalated SR/C20A < highly exfoliated SR/C30B. The thermogravimetric analyses of the SR/C30B nanocomposite showed a substantial increase in the final residue in comparison with the neat SR. This indicated a major improvement in the thermal stability of the rubber containing the exfoliated clay, which was also supported by the higher activation energy of decomposition measured for the nanocomposite.
\end{abstract}




\section{INTRODUCTION}

The past decade has seen rapid advances in the field of silicone rubber/clay nanocomposite. Montmorillonite (MMT) clay has been widely investigated due to its unique properties that offer high aspect ratio within nanoscale range [1-8]. Studies have shown that basic mechanical properties such as tensile strength, elongation at break and Young's modulus were dramatically improved with regard to the neat silicone rubber (SR) by the addition of clay as low as $10 \mathrm{wt} \%$ [7-8]. In addition to its good effects on rubber properties, clay is relatively cheaper than other fillers such as carbon black and synthetic silica. Hence, it is believed that using cost-effective materials such as clay will have potential benefits to manufacturers of rubber goods under the current economic climate.

In line with the recent development of SR/clay nanocomposite, there is increasing concern on how clay affects thermal degradation and stability of silicone rubber particularly at high temperature applications. Lewicki and co-workers [9] observed a major change in the physical and chemical structure of the polymer-filler network in some SR/Cloisite $6 \mathrm{~A}$ nanocomposites after ageing the rubbers at $150^{\circ} \mathrm{C}$ for $504 \mathrm{~h}$ in moisture air and dry nitrogen. It emerged that a major re-structuring of the polymer-filler network that involved aged chain scission, backbiting and recombination had taken place in the nanocomposites upon ageing due to thermodynamic reformation to achieve stable network. However, the mechanical properties of the aged nanocomposites were not measured in their study. 
Kong et al. [10] observed that the addition of modified montmorillonite (OMT) enhanced the thermal stability of SR/clay nanocomposite significantly. From the thermogravimetric analysis (TGA), it showed that both onset degradation temperature $\mathrm{T}_{0.1}(10 \%$ degradation occurs $)$ and midpoint of degradation process, $\mathrm{T}_{0.5}(50 \%$ degradation occurs) of the SR/Fe-MMT and SR/Na-MMT nanocomposites were higher as compared to the neat SR. In comparison, the SR/Fe-MMT nanocomposite had better thermal stability than the SR/Na-MMT one due to the advantage of iron $\left(\mathrm{Fe}^{3+}\right)$ that acted as an antioxidant.

Comparing the thermal degradation characteristics obtained from the TGA tests on room temperature vulcanized (RTV) SR filled with natural ( $\left.\mathrm{Na}^{+} \mathrm{MMT}\right)$, quaternary ammonium salts (QAS) modified MMT (OMMT), and hyperbranched QAS (HQAS) modified MMT (HOMMT), the rubber filled with $3 \mathrm{wt} \%$ HOMMT exhibited higher $\mathrm{T}_{\text {onset }}$ than the other counterparts due to uniform dispersion of the filler particles and stronger rubber/filler interactions [11]. But to some extent, the rubber filled with $\mathrm{Na}^{+} \mathrm{MMT}$ presented a higher center temperature of thermal degradation $\left(T_{\max }\right.$, the temperature at which weight loss is the fastest). In addition, the yield residue of the rubber with $\mathrm{Na}+\mathrm{MMT}(77.8 \%)$ was far higher than the ones filled with OMMT (51.5\%) and HOMMT $(53.2 \%)$ fillers. It was concluded that the higher ratio of inorganic silicate layers in the $\mathrm{Na}+\mathrm{MMT}$ filler had improved the thermal stability of the rubber [11].

Lewicki and co-workers [12] observed different thermal degradation behavior of some SR/MMT nanocomposites. They noticed that the inclusion of Cloisite 6A (MMT modified with quarternary alkyl ammonium cations) significantly altered the non- 
oxidative degradation behavior and modified the thermal degradation profile, hence exhibiting a negative impact on the thermal stability of the rubber. It was concluded that at high temperatures, i.e. $400-500^{\circ} \mathrm{C}$, the clay promoted radical cleavage reaction as indicated by the formation of benzene and dimethylsiloxane based on thermal vitalization analysis (TVA). The production of above byproducts was associated with the level of side radicals that contributed to the reduction of thermal stability. It was suggested that Cloisite $6 \mathrm{~A}$ probably acted as a pro-degradant within the SR matrix due to the acid sites on the clay platelets or breakdown of the organic modifier. Interestingly, at clay loading above $2 \mathrm{wt} \%$, this phenomenon became less dominant. In addition, the physical barrier properties improved when the clay loading increased to $8 \mathrm{wt} \%$ [12].

There has been relatively little work done to measure mechanical properties of SR/MMT nanocomposites after ageing at elevated temperatures, e.g. $200^{\circ} \mathrm{C}$. Also, there has been little consensus on effect of clay on the thermal stability of SR/clay nanocomposites. Thus, the present study investigated effects of montmorillonite clay on the heat ageing and thermal stability of some SR/clay nanocomposites. Notably, recent reviews emphasized the importance of clay dispersion such as intercalation and exfoliation on the heat resistance and thermal degradation of rubber nanocomposites [13].

With this in mind, this study used nanocomposites with highly exfoliated Cloisite 30B (SR/C30B), highly intercalated Cloisite 20A (SR/C20A), and intercalated/exfoliated Cloisite $\mathrm{Na}^{+}\left(\mathrm{SR} / \mathrm{Na}^{+} \mathrm{MMT}\right)$. The properties of the unaged and aged nanocomposites such as tensile strength, Young's modulus and elongation at break were compared with 
the neat SR. The results indicated that the SR/C30B nanocomposite exhibited excellent resistance to heat ageing when compared with the other two nanocomposites and the neat SR. Also, thermal degradation behavior of the SR/MMT nanocomposites in air and nitrogen were very different. The enhancement of final residue in thermo-oxidative degradation was highly dependent on the dispersion state of MMT in the rubber matrix. A noticeable enhancement in the thermal stability of the SR/C30B nanocomposite containing exfoliated clay was observed which was confirmed by the thermogravimetric analysis of the rubber samples. However, effect of MMT morphology on thermal degradation of the rubber in a nitrogen atmosphere was inconclusive. Interestingly, the presence of organic surfactant in the modified MMT influenced the thermal stability of the nanocomposites in the inert atmosphere.

\section{EXPERIMENTAL}

\section{Materials}

The raw rubber used was polydimethyl siloxane Silastic (R) SGM-26 with a molecular weight of about 300,000 . It was a random copolymer in which some of the methyl groups were substituted with vinyl ones, producing vinyl dimethyl silicone rubber. The end groups were vinyl siloxane. The vinyl content was 0.12 wt\% (Dow Corning Limited, UK). A high purity (99\%) dicumyl peroxide (DCP) or bis( $\alpha, \alpha$-dimethylbenzyl) was used as a vulcanizing agent (Fisher Scientific, UK). In addition, commercial Cloisite 30B and Cloisite 20A organoclays were also used, which were modified with different functional treatments namely methyl, tallow, bis-2-hydroxyetyl, quaternary ammonium (MT2EtOH), and dimethyl, dehydrogenated tallow, quaternary ammonium (2M2HT), respectively. 
The pristine montmorillonite was referred to as Cloisite $\mathrm{Na}+$. Both unmodified and modified clays were supplied by Southern Clay Product, USA.

\section{Preparation of SR/clay nanocomposites}

Three rubber compounds based on Cloisite $\mathrm{Na}+$, Closite 30B and Cloisite 20A were made at a loading of 6 parts per hundred rubber by weight (phr). An unfilled silicone rubber compound was also prepared as a control compound (neat SR) by mixing the raw rubber with $0.3 \mathrm{phr}$ dicumyl peroxide, which was sufficient to fully cure the neat SR as well as the nanocomposites [14]. Prior to mixing, the clays were dried in a vacuum oven at $60^{\circ} \mathrm{C}$ for 48 hours to remove moisture. The rubber and all the compounding ingredients were then mixed in a Polylab mixer OS (ThermoHAAKE, Germany), using counter-rotating type Banbury rotors. The mixing chamber was set at $20^{\circ} \mathrm{C}$ and the rotor speed was set at 50 r.p.m. At first, the raw rubber was placed in the mixer and then clay was added and mixed for $10 \mathrm{~min}$. Then peroxide was added and mixed for another 5 min after which the rubber compound was removed and cool down before placing it in a clean plastic bag. Twenty four hours after mixing, an oscillating disc rheometer (ODR) (Monsanto, Swindon, UK) was used to measure the cure properties of the rubber compounds at $160^{\circ} \mathrm{C}$. The rubber compounds were subsequently cured in a compression mould at $160^{\circ} \mathrm{C}$ and $20 \mathrm{MPa}$ pressure to produce sheets about $2 \mathrm{~mm}$ thick for further work.

\section{Characterizations method}

$X$-ray diffraction $(X R D)$ analysis 
The X-ray diffraction (XRD) spectra of the layered silicates and SR/MMT nanocomposites were produced on a Bruker D8 diffractometer (Bruker, Germany). The diffractometer was equipped with $\mathrm{Cu}$ Ka radiation $(\lambda=0.15418 \mathrm{~nm}), 40 \mathrm{~mA}$ of current and $40 \mathrm{kV}$ of voltage. A minimum of $3 \mathrm{~g}$ of dried clay powder was used to carry out the X-ray analysis of the mineral clays. A square flat sheet, $30 \mathrm{~mm}$ by $30 \mathrm{~mm}$ and $2 \mathrm{~mm}$ thick, of the cured rubber was used for the X-ray analysis of the nanocomposites. The experiment was performed at low angle in the range $2 \theta=1-10^{\circ}$ with the scan rate of $0.02 \%$ second. In addition, the spacing between the structural layers of the silicates was measured according to the Bragg's law (equation 1), where $n$ is an integer, $\lambda$ is the $X$ ray wavelength, $d$ is the interlayer spacing, and $\theta$ is the angle of diffraction.

$$
\lambda n=2 d \sin \theta
$$

\section{Transmission electron microscopy (TEM)}

Dispersion of the clay particles in the rubber matrix was investigated by a transmission electron microscopy (TEM) model 2000FX (JEOL, Japan). Ultra-thin sections were prepared by cryo-ultramicrotomy model CR-X (RMC, USA). The sectioning process was carried out at $-150^{\circ} \mathrm{C}$, using a diamond knife with a cutting edge of $45^{\circ}$. The cryosections thickness was set at $100 \mathrm{~nm}$. Sections of rubber were collected on a copper grid and examined with TEM model 2000FX (JEOL, Japan). The operating accelerating voltage of TEM was $80 \mathrm{kV}$.

Accelerated ageing tests 
Accelerated ageing by heating in air was carried out according to the procedure described in BS $903-\mathrm{A} 19$ [15]. The samples were aged in an oven at $200^{\circ} \mathrm{C}$ for 10,20 , 24 and $30 \mathrm{~h}$, respectively with no strain on them. The tensile properties of the aged samples were then measured in uniaxial tension in a Lloyd testing machine LR50K (Hampshire, UK) with standard dumbbell test pieces at $24^{\circ} \mathrm{C}$ and a cross-head speed of $100 \mathrm{~mm} / \mathrm{min}$ according to BS903: Part A2;1995. Lloyd Nexygen 4.5.1 computer software was used to store and process the data. Five test pieces were tested for each rubber compound and the median of the values were subsequently noted. Finally, the results were expressed based on \% retention ((aged $\div$ unaged $) \times 100)$.

Fourier transforms infra-red spectroscopy (FTIR)

An Infrared (IR) spectrometer model FTIR-8400S (Shimadzu, Japan) was utilized to analyze surface chemistry of the rubber samples. Attenuated total reflectance (ATR) technique was also used as it was suitable for solid samples. The spectra were obtained in the range $600-4000 \mathrm{~cm}^{-1}$ after 64 scans were completed.

Thermogravimetric analysis (TGA)

Thermogravimetric analysis (TGA) was conducted with a model Q5000IR (TA Instruments, United Kingdom). The $12-15 \mathrm{mg}$ specimens were heated from ambient temperature $\left(\sim 23^{\circ} \mathrm{C}\right)$ to $800^{\circ} \mathrm{C}$ with a linear heating rate of $10^{\circ} \mathrm{C} \mathrm{min}^{-1}$. The TGA analyses were performed in air and in nitrogen atmospheres at a flow rate of $60 \mathrm{~mL} \mathrm{~min}{ }^{-1}$. Details on thermal degradation such as onset of degradation temperature, 
( $T_{\text {onset, }}$, the temperature at which mass loss is $5 \%$ ), temperatures for $10 \%$ and $50 \%$ mass loss $\left(T_{10}\right.$ and $\left.T_{50}\right)$, and residue mass at $650^{\circ} \mathrm{C}$ were recorded.

In order to understand the depolymerisation mechanism of the neat SR and nanocomposites, DTG curves (derivative of the residual weight \% versus temperature) in air and in nitrogen were also analyzed. The DTG plots were prepared based on derivative of the mass change with respect to temperature $(\mathrm{dm} / \mathrm{dT})$ as a function of temperature. Thus, in a DTG plot, the peak height gives the rate of mass change at any temperature or the rate of degradation.

Kinetic analysis of the thermal degradation of the neat $S R$ and nanocomposites

Activation energies against conversion levels in the range $1-20 \%$ during the thermal oxidative degradation of the neat SR and nanocomposites were determined using ASTM E1641-07 [16], which follows the well-known Flynn-Wall-Ozawa method [17]. A rapid TGA test of the studied materials was carried out based on three different heating rates, $5^{\circ} \mathrm{C} \mathrm{min}-1,10^{\circ} \mathrm{C} \mathrm{min}-1$ and $20 \mathrm{~min}^{-1}$. The activation energy was then calculated using equation 2 :

$$
E=-\left(\frac{R}{b}\right) * \Delta(\log \beta) / \Delta(1 / T)
$$

where $E$ is Arrhenius activation energy $(\mathrm{J} / \mathrm{mol}), \mathrm{R}$ is gas constant $(8.314(\mathrm{~J} / \mathrm{mol} . \mathrm{K}), \mathrm{b}$ is a constant $(0.457 / \mathrm{K})$ measured by Flynn and Wall [17], $\beta$ is a heating rate $\left({ }^{\circ} \mathrm{C} / \mathrm{min}\right)$ and finally, $\mathrm{T}$ is temperature at constant conversion. 


\section{RESULTS AND DISCUSSION}

\section{Microstructure of the rubber nanocomposites}

Figure 1 shows the XRD spectra of Cloisite $\mathrm{Na}+$, Closite 30B, and Cloisite 20A clays, and the nanocomposites filled with $6 \mathrm{phr}$ of the fillers. It has been reported that 6 phr of the clays was the optimum level to produce highly intercalated/exfoliated morphology in rubber nanocomposites [18]. Notably, a broad peak was seen at $2 \theta=4.5-5.5^{\circ}$ for the $\mathrm{SR} / \mathrm{Na}^{+} \mathrm{MMT}$ nanocomposite and for the Cloisite $\mathrm{Na}+, 2 \theta$ was at $7.2^{\circ}$. This meant that the peak position had shifted to a lower angle, indicating formation of intercalated structure. However, intensity of the intercalated peak was rather small and almost disappeared. Probably, some of the Cloisite $\mathrm{Na}^{+}$filler particles transformed into single platelets when the layered structure broke down. Thus, it was believed that the SR/Na ${ }^{+} \mathrm{MMT}$ nanocomposite contained both intercalated and exfoliated morphologies.

In the case of SR/C30B nanocomposite, the XRD peak had disappeared. The absence of peak on the XRD spectrum was due to break down of the layered structure which produced exfoliated platelets or an increase in the basal spacing between the layers (intercalated structure) that could not be detectable by XRD [19]. In contrast, Cloisite 20A and the SR/20A nanocomposite showed clear peaks for $d_{001}$ and $d_{002}$ at $2 \theta$ $=2.55^{\circ}$ and $2 \theta=5.10^{\circ}$, respectively. Since the peak position was shifted to a lower angle, it was concluded that the clay had intercalated in the rubber matrix. According to Brag's equation, the $\mathrm{d}$ spacing of Cloisite $20 \mathrm{~A}$ had expanded by $0.89 \mathrm{~nm}$ from its original value of $2.57 \mathrm{~nm}$. 
The filler morphology in the rubber matrix was further investigated at high magnifications as shown in TEM micrographs (Fig. 2(a-c)). The fine and thick dark lines seen in these figures corresponded to the cross-section of individual clay layers and a typical sandwich layer, respectively. In Fig. 2a, a number of intercalated Cloisite $\mathrm{Na}+$ particles were seen in the rubber matrix (shown by white arrows). In addition, on the same figure, it was evident that some filler particles approximately $1 \mathrm{~nm}$ thick were dispersed individually in the rubber matrix (shown by black arrows). Note that, the XRD results in Fig.1 did not reveal spatial distribution of the platelets. Therefore, after considering the results in Figs. 1 \& 2a, it was concluded that both exfoliated and intercalated clay structures were present in the rubber matrix.

Fig. $2 \mathrm{~b}$ shows nanoscale dispersion of the Cloisite $30 \mathrm{~B}$ layers in the rubber matrix. Thin dark lines in the figure represent exfoliated platelets (shown by black arrows). In this case, information obtained from XRD (Fig. 1) agreed well with that seen in Fig. 2b. It was obvious that only a few thick dark lines, representing stacked layers were also present in the figure (as indicated with white arrows). Thus, it was concluded that highly exfoliated Cloisite 30B clay particles were present in the rubber matrix. Fig. 2c shows dispersion of the clay in the SR/C20A nanocomposite. Intercalated Cloisite $20 \mathrm{~A}$ can be seen clearly as indicated by the white arrows. It seemed that the interlayer spacing had expanded due to diffusion of the rubber chains into the stacked layer [20]. This observation was also confirmed in Fig. 1.

Thermal aging properties of the rubbers at $200^{\circ} \mathrm{C}$ as a function of ageing time 
As mentioned earlier, the thermal ageing tests were performed at $200^{\circ} \mathrm{C}$ for $0 \mathrm{~h}$, 10 h, 20 h, 24 h and 30 h durations. Evidently, the tensile strength, Young's modulus and elongation at break of the neat SR and nanocomposites deteriorated when the ageing time was increased (Table 1). This was due to a degradation process that occurred at this temperature. An earlier study showed that changes in the mechanical properties of a methyl vinyl SR during ageing was mainly due to network scission or network formation, i.e. crosslinking, or perhaps a combination of both of these processes [21, 22].

For a clear comparison, thermal ageing properties of the neat $S R$ and nanocomposites were characterized based on \% retention $(($ aged $\div$ unaged $) \times 100)$ as displayed in Figs. 3(a-c). Fig. 3a compares the tensile strength against ageing time for the neat SR and nanocomposites. The tensile strength of the neat SR reduced sharply after $10 \mathrm{~h}$ and then continued deteriorating albeit at a much slower rate when the rubber was aged for $30 \mathrm{~h}$. A similar trend was also observed for the nanocomposites but the strength of the rubber was not affected as much by ageing. This suggested that the clay protected the rubber against ageing because the nanocomposites performed considerably better than the neat SR. Overall, a large reduction in the tensile strength of both the neat SR and nanocomposites was noticed but the SR/C30B nanocomposite was the best performing material.

Fig. $3 b$ displays \% retention of the Young's modulus against ageing time for the neat SR and nanocomposites. The Young's modulus of the neat SR decreased noticeably after ageing for $10 \mathrm{~h}$ but the decay slowed down after $20 \mathrm{~h}$. It was interesting 
that there was an improvement in the Young's modulus after $24 \mathrm{~h}$, followed by a modest reduction thereafter. This small increase was due to a rise in crosslink density. It has been reported that chain scission in the SR bonds was largely due to hydrolysis reaction at temperatures below $250^{\circ} \mathrm{C}[21,22]$. Concurrently, the methyl side groups might have gradually oxidized after a long term exposure to heat ageing, causing a rise in crosslink density [20]. This might explain the modest improvement observed in the modulus of the rubber after $24 \mathrm{~h}$ of ageing. Tomer and co-workers investigated effect of different ageing processes including thermal ageing on various grades of silicone rubber using Gel Permeation Chromatography (GPC). GPC showed that the aged samples were more crosslinked. In the case of thermal ageing at $100^{\circ} \mathrm{C}$, during the first hours the increase of molecular weight was modest and then quite stable [23]. Our results are in line with their findings.

For the nanocomposites, the Young's modulus decreased sharply after $10 \mathrm{~h}$ but the decline was less severe when the rubber was aged for another $10 \mathrm{~h}$. Afterward, there was a very rapid recovery particularly for the SR/C30B and SR/Na ${ }^{+} \mathrm{MMT}$ nanocomposites when the samples were aged for an extra $4 \mathrm{~h}$. However, the modulus decreased for both nanocomposites after they were aged for $6 \mathrm{~h}$ longer. The modulus of the SR/C20A nanocomposite remained inferior over the $30 \mathrm{~h}$ ageing test.

Fig. 3c demonstrates the elongation at break of the neat SR and nanocomposite as a function of ageing time. For the neat SR, there was no change in this property for up to $20 \mathrm{~h}$ but it decreased steeply when the rubber was aged for another $10 \mathrm{~h}$. The nanocomposites showed superior properties although they performed differently as they 
were aged. For example, the SR/C30B nanocomposite retained its elongation at break better than the other two which had similar values after $20 \mathrm{~h}$ ageing. Afterwards, the elongation at break of the neat SR and nanocomposites dropped sharply, indicating a very severe deterioration in the elasticity of the rubber.

From the results presented in Figs. 3a-b, it was evident that the nanocomposites performed differently after they were aged for $24 \mathrm{~h}$. This was probably due to increase in crosslink density which was responsible for improvement in the Young's modulus and loss of elongation at break of the SR/C30B and SR/Na ${ }^{+} \mathrm{MMT}$ nanocomposites as shown in Fig. 3b and Table 1. A similar phenomenon was reported earlier for a silicone rubber filled with silica nanofiller [21]. It was speculated that silanol groups $(\mathrm{SiOH})$ on the silica surface caused cleavage of the rubber chains. The bonding of the cleaved rubber chains to silica resulted in an increase in crosslink density and loss of mechanical properties [21]. In this case, it is likely that the presence of $\mathrm{OH}$ groups in the organic modifier (methyl, tallow, bis-2-hydroxyetyl, quaternary ammonium) and the edges of silicate layers in Cloisite $30 \mathrm{~B}$ and Cloisite $\mathrm{Na}^{+}$clays, respectively were responsible for the increase in crosslink density. However, it is probable that this phenomenon did not occur in the SR/C20A nanocomposite because Cloisite 20A had no OH groups

On the other hand, morphology of the clay had a noticeable effect on the heat resistance of the rubber and generally, the incorporation of the clays was beneficial to the thermal properties of the rubber. Therefore based on the results, effect of the clay morphology on the thermal resistance of the rubber can be summarized as following: 
exfoliated SR/C30B nanocomposite > intercalated/exfoliated SR/Na ${ }^{+} \mathrm{MMT}>$ intercalated SR/C20A nanocomposite.

These findings suggest that in general presence of the clays enhanced the heat resistance of the rubber as reflected by higher retention strength of the nanocomposites with regard to the neat SR. This behavior has been rarely reported in the case of nonhydrocarbon polymers such as SR. According to Pielichowski and Njuguna [24], besides the chemical nature of SR end-caps, the rate of degradation in SR at high temperatures is increased due to some external factors such as acidic or basic impurities, oxygen, water, fillers and residual catalyst. However, in this case, presence of the clays has been shown to stabilize the SR structure against thermal degradation.

Interestingly, this phenomenon was observed in all the nanocomposites tested, suggesting that both the unmodified and modified clays had prevented the SR chains from scission during ageing tests. Nevertheless, the inclusion of C30B clay showed the highest resistance to heat ageing among the other corresponding clays. As expected, among the rubbers tested, the SR/C30B nanocomposite containing exfoliated clay exhibited the best resistance to ageing. Presumably, strong rubber-filler interaction offered by large available surface area of the exfoliated clay platelets reduced chain mobility and helped to minimize chain scission. This was supported by evidence from chemical analysis of the SR/C30B nanocomposite surface as revealed by the ATR-FTIR spectra in Figs. 4(a-b).

Likewise, the results obtained were consistent with the observations made by Choudhury and co-workers [25]. They reported that the addition of Cloisite 30B 
improved the retention of physico-mechanical properties of a hydrogenated nitrile rubber (HNBR) by disrupting the oxidative process. The enhancement of thermal stability of the HNBR/C30B nanocomposite was attributed to the interaction between intercalated polymer chains and the clay layers which formed hydrogen bonding between $\mathrm{OH}$ groups on the clay surface and the polar groups $(\mathrm{CN})$ present in the rubber.

\section{ATR-FTIR analysis of the rubber samples}

An attempt was made to measure changes in surface chemistry of the neat SR and SR/30B nanocomposite before and after ageing using a transmission FTIR. IR scans of the unaged and aged samples at $200^{\circ} \mathrm{C}$ for 20 and $24 \mathrm{~h}$ were analyzed as shown in Figs.4 (a-b). There were three distinct characteristic peaks on the spectra of the rubber samples. A sharp peak at $1257 \mathrm{~cm}^{-1}$ was induced by the deformation of Si$\mathrm{CH}_{3}$, and the stretching of Si-C contributed to a clear band at $785 \mathrm{~cm}^{-1}$. Moreover, Si-OSi backbone produced a broad band with two maxima at 1009 and $1078 \mathrm{~cm}^{-1}$. It has been reported that weak bands at $1610,1561 \mathrm{~cm}^{-1}, 1460$ and $1409 \mathrm{~cm}^{-1}$ peaks were evidence of crosslinking networks in SR [26].

Note that no significant change was observed when the IR spectra of the unaged and aged samples of the neat SR were compared in Fig. 4a. All the characteristic peaks of the neat SR remained constant in a similar position even after ageing. But intensity ratio of Si-O vibration $\left(1009 \mathrm{~cm}^{-1}\right.$ and $\left.1078 \mathrm{~cm}^{-1}\right)$ rapidly decreased with increasing ageing time. An obvious reduction of intensity ratio was detected for absorption bands at $783 \mathrm{~cm}^{-1}$, which corresponded to $\mathrm{Si}-\mathrm{CH}_{3}$. It was found that the intensity ratio of Si$\mathrm{CH}_{3}$ band was decreased from 1.42 for the unaged to 1.21 for the aged sample after 
ageing at $200^{\circ} \mathrm{C}$ for $24 \mathrm{~h}$. Rapid decrease of the characteristic peaks suggested that the Si-O-Si backbone underwent a chain scission at $200^{\circ} \mathrm{C}$ to form shorter chains.

In addition, no new peaks were observed in the spectra, which indicated no oxidative product was formed during the ageing process (Fig. 4a). Interestingly, appearance of small absorption peaks at 1610 and $1561 \mathrm{~cm}^{-1}$, and 1460 and $1409 \mathrm{~cm}^{-1}$ positions could be assigned mainly to the formation of crosslink network in SR as suggested by some workers [26]. It has been reported that the peak near $1411 \mathrm{~cm}^{-1}$ corresponded to the rocking vibration of $-\mathrm{CH}_{2}$ as a part of the rubber cross-linked domain [27]. In this case, a sharpening of weak peaks at 1411 and $1593 \mathrm{~cm}^{-1}$ was noticeable with increasing ageing time from 20 to $24 \mathrm{~h}$ as shown in Fig. 4(b). The absorption peak at $1411 \mathrm{~cm}^{-1}$ was increased from 0.041 to 0.048 , and $1593 \mathrm{~cm}^{-1}$ from 0.016 to 0.025 , respectively. The increase in intensity ratio suggested that more crosslinks were formed in the rubber as a function of ageing time and this explained the improvement in the Young's modulus (Fig. 4b). The brittleness of SR after long exposure to air at $200^{\circ} \mathrm{C}$ was attributed to a mild oxidative crosslinking reaction of the methyl side groups in the main chain of the polymer [21].

Figs. 5(a-b) illustrate IR band for the SR/C30B nanocomposite before and after ageing for 24 and $30 \mathrm{~h}$. Similar to the neat SR, no significant change was noticed in the IR spectrum of the rubber. The peak intensity of $\mathrm{Si}-\mathrm{O}$ and $\mathrm{Si}_{-} \mathrm{CH}_{3}$ bands showed no change during ageing and this indicated no serious degradation of the rubber. It appeared that the addition of clay protected the rubber from chain scission, direct oxidation and hence degradation. This might explain why the nanocomposite was more 
resistance to heat ageing as compared to the neat SR as discussed in the earlier section. Similar to the neat SR, the increase of small peak intensity ratios at 1610 and $1561 \mathrm{~cm}^{-1}$, and 1460 and $1409 \mathrm{~cm}^{-1}$ positions showed some evidence of light crosslinking in the rubber with increasing the ageing time (Fig. 5b).

\section{Thermal-oxidative degradation of the SR/MMT nanocomposites}

Thermogravimetric analysis (TGA) of the nanocomposites was carried out in air and nitrogen atmospheres. To evaluate improvement in the thermal properties of the rubbers containing the clays, the results were compared with the neat SR. Fig. 6 displays TGA curves of the nanocomposites in air. The details of thermal-oxidative degradation in air are also summarized in Table 2.

Based on the results shown in Fig. 6 and Table 2, it was clear that the addition of the clays delayed depolymerisation of the rubber during the thermal oxidative degradation. For example, the onset temperature $T_{\text {onset }}$ (the temperature at which $5 \%$ of weight loss appears) of the SR/Na ${ }^{+} \mathrm{MMT}, \mathrm{SR} / \mathrm{C} 30 \mathrm{~B}$ and SR/C20A nanocomposites were $340^{\circ} \mathrm{C}, 340^{\circ} \mathrm{C}$ and $342^{\circ} \mathrm{C}$, respectively, which were $8-10^{\circ} \mathrm{C}$ higher than that of the neat SR. The $\mathrm{T}_{\text {onset }}$ of the neat $\mathrm{SR}$ was $332^{\circ} \mathrm{C}$. When a comparison was made among the nanocomposites, the results suggested that the $T_{\text {onset }}$ was not affected by the intercalation or exfoliation of the clay particles in the rubber.

Nevertheless, further analysis revealed that the clay morphology did influence the thermal stability of the rubber for $T_{10}$ and $T_{50}$, respectively. With the addition of $\mathrm{Na}^{+} \mathrm{MMT}, \mathrm{C} 30 \mathrm{~B}$ and $\mathrm{C} 20 \mathrm{~A}$ clays, the $\mathrm{T}_{10}$ (the temperature at which $10 \%$ of weight loss 
appears) was shifted to $367^{\circ} \mathrm{C}, 375^{\circ} \mathrm{C}$ and $378^{\circ} \mathrm{C}$, respectively as compared to the neat SR. The $T_{10}$ of the neat $S R$ was $345^{\circ} \mathrm{C}$. Interestingly, the $T_{50}$ as midpoint temperature of degradation process of the rubber was markedly improved with the inclusion of the clays. With regard to the neat SR, the $T_{50}$ of the SR/Na ${ }^{+} M M T, S R / C 30 B$ and SR/C20A nanocomposites were moved from $396^{\circ} \mathrm{C}$ (for the neat SR) to $478^{\circ} \mathrm{C}, 495^{\circ} \mathrm{C}$ and $484^{\circ} \mathrm{C}$ respectively.

It was evident that effect of the exfoliated platelets of C30B clay on the thermal degradation was more pronounced at higher temperatures, since the $T_{50}$ of the $\mathrm{SR} / \mathrm{C} 30 \mathrm{~B}$ nanocomposite was about $99^{\circ} \mathrm{C}$ higher than that of the neat SR. It has been reported that oxidation reaction of the main SR chains was dominant at temperatures above $250^{\circ} \mathrm{C}$ [22]. In this case, with the presence of exfoliated $\mathrm{C} 30 \mathrm{~B}$ in the rubber matrix, oxidation reaction was delayed due to barrier performance of the clay platelets.

In addition, this result corresponded well to the improvement of the mass residue at $650^{\circ} \mathrm{C}$. As described in Table 2, the residue for the neat SR was about $22.3 \%$. However, in the presence of the exfoliated C30B clay platelets in the rubber, the mass residue increased significantly to $42.0 \%$. This followed by the intercalated C20A and intercalated/exfoliated $\mathrm{Na}^{+} \mathrm{MMT}$ clays where the remaining residue increased to $37.4 \%$ and $30.5 \%$, respectively. Clearly, a noticeable improvement was observed for the exfoliated SR/C30B nanocomposite, which had $88 \%$ additional final residue compared to the neat SR. Evidently, enhancement of the final residue in the thermo-oxidative degradation was highly dependent on the dispersion state of the clay particles in the rubber matrix. 
Degradation rate of the nanocomposites was compared with the neat SR based on the DTG data shown in Figs. 7(a-c) and Table 2. Note that Fig 7 corresponds to the TGA curves presented in Fig. 6. The results showed that the neat SR experienced two major thermal-oxidative degradation stages at $356^{\circ} \mathrm{C}$ and $406^{\circ} \mathrm{C}$. Unlike the neat $\mathrm{SR}$, on average the DTG plots of the nanocomposites were more complex and not well defined. This indicated that the use of the clays in the rubber had modified the degradation behavior significantly. The SR/Na ${ }^{+} \mathrm{MMT}$ and SR/C30B nanocomposites exhibited two maxima, respectively (Figs. $7 a \&$ b) above $360^{\circ} \mathrm{C}$. However, the SR/C20A nanocomposite displayed three maxima above this temperature (Fig. 7c). In this case, small peaks that appeared at $356^{\circ} \mathrm{C}$ in the DTG plots (Fig. $7 \mathrm{c}$ ) of the nanocomposites were neglected because they represented low degradation rate.

Based on $\mathrm{T}_{\max }$ results in Table 2, degradation of the nanocomposites shifted to higher temperatures when compared with the neat SR. For example, the $T_{01}$ (temperature for first step degradation) of the SR/Na ${ }^{+} \mathrm{MMT}, \mathrm{SR} / \mathrm{C} 30 \mathrm{~B}$ and SR/C20A nanocomposites shifted from $356^{\circ} \mathrm{C}$ (for the neat SR) to $390^{\circ} \mathrm{C}, 385^{\circ} \mathrm{C}$ and $395^{\circ} \mathrm{C}$ respectively. This corresponded well with the degradation rate for $T_{01}$ of the $\mathrm{SR} / \mathrm{Na}^{+} \mathrm{MMT} \quad\left(1.35 \% /{ }^{\circ} \mathrm{C}\right), \quad \operatorname{SR} / \mathrm{C} 30 \mathrm{~B} \quad\left(0.60 \% /{ }^{\circ} \mathrm{C}\right)$ and $\quad \mathrm{SR} / \mathrm{C} 20 \mathrm{~A} \quad\left(0.65 \% /{ }^{\circ} \mathrm{C}\right)$ nanocomposites, which were lower than the neat SR $\left(1.59 \% /{ }^{\circ} \mathrm{C}\right)$. Evidently, the above changes were more pronounced for the SR/C30B and SR/20A nanocomposites that contained highly exfoliated and intercalated clay particles, respectively. It appeared that the oxidative reaction in the SR chains that normally occurs at above $250^{\circ} \mathrm{C}$ [20] was retarded by the presence of the clays and this in turn reduced the degradation rate of the nanocomposites. 
Similarly, the $\mathrm{T}_{02}$ (temperature for second step degradation) of the SR/Na ${ }^{+} \mathrm{MMT}$ $\left(468^{\circ} \mathrm{C}\right), \mathrm{SR} / \mathrm{C} 30 \mathrm{~B}\left(411^{\circ} \mathrm{C}\right)$ and $\mathrm{SR} / \mathrm{C} 20 \mathrm{~A}\left(442^{\circ} \mathrm{C}\right)$ nanocomposites increased to higher values when compared with the neat $S R$ which was at $406^{\circ} \mathrm{C}$. This indicated that the rubber became thermally stable with the addition of the clays. However, the degradation rate $\mathrm{T}_{02}$ for the $\mathrm{SR} / \mathrm{C} 30 \mathrm{~B}\left(0.78 \% /{ }^{\circ} \mathrm{C}\right)$ and $\mathrm{SR} / \mathrm{C} 20 \mathrm{~A}\left(0.60 \% /{ }^{\circ} \mathrm{C}\right)$ nanocomposites were rather higher than the neat $\mathrm{SR}$ which was at $0.58 \% /{ }^{\circ} \mathrm{C}$. This showed that the degradation rate of the nanocomposites accelerated towards higher temperatures.

In contrast, the degradation rate of the nanocomposite containing the intercalated/exfoliated $\mathrm{Na}^{+} \mathrm{MMT}$ particles was slightly lower $\left(0.53 \% /{ }^{\circ} \mathrm{C}\right)$ than the neat $\mathrm{SR}$ $\left(0.58 \% /{ }^{\circ} \mathrm{C}\right)$. This implied that the depolymerisation reaction in this nanocomposite was less aggressive at higher temperatures when compared to the other two nanocomposites. This behavior was probably related to the absence of organic surfactant in the unmodified $\mathrm{Na}^{+} \mathrm{MMT}$ clay.

It was clear that the exfoliated C30B clay platelets were the most effective barrier against diffusion of oxygen into the rubber during the thermal oxidative degradation, hence increasing the thermal stability of the nanocomposite. Mechanism of barrier performance in polymer/clay nanocomposites was well explained in a previous study [13]. It was suggested that exfoliated clay particles acted as physical barrier and averted oxygen from diffusing into the nanocomposite. In addition, during the thermal degradation process, the depolymerised products were prevented from moving to the combustion interface by the exfoliated clay platelets. Therefore, this phenomenon might 
explain the better performance of the SR/C30B nanocomposite in the thermal oxidative degradation tests.

\section{Thermal degradation of the nanocomposites in nitrogen atmosphere}

The thermal degradation of the neat SR and nanocomposites was measured in a nitrogen atmosphere. TGA plots of the neat SR and nanocomposites are presented in Fig. 8. As expected, the TGA data of the nanocomposites were notably different from those of the neat SR. Table 3 summarizes the thermal properties such as $T_{\text {onset }}, T_{10}, T_{50}$, final residue and $T_{\max }$ of the rubbers tested.

The addition of $\mathrm{Na}^{+} \mathrm{MMT}$ and $\mathrm{C} 30 \mathrm{~B}$ clays increased the $\mathrm{T}_{\text {onset }}$ of the neat SR which was originally at $370^{\circ} \mathrm{C}$ by about $8^{\circ} \mathrm{C}$ to $9^{\circ} \mathrm{C}$. A similar behavior was also seen for the $\mathrm{T}_{10}$ as shown in Table 3. For example, $\mathrm{T}_{10}$ of the $\mathrm{SR} / \mathrm{Na}^{+} \mathrm{MMT}$ and $\mathrm{SR} / \mathrm{C} 30 \mathrm{~B}$ nanocomposites were shifted to $405^{\circ} \mathrm{C}$ and $411^{\circ} \mathrm{C}$, respectively whereas the $\mathrm{T}_{10}$ of the neat SR was at $399^{\circ} \mathrm{C}$. However, the SR/C20A nanocomposite started to degrade slightly earlier than the neat SR. The $T_{\text {onset }}$ and $T_{10}$ of this nanocomposite were $368^{\circ} \mathrm{C}$ and $397^{\circ} \mathrm{C}$, respectively. These values were marginally lower than the ones measured for the neat SR at $370^{\circ} \mathrm{C}$ and $399^{\circ} \mathrm{C}$, respectively (Table 3).

A significant difference in the thermal degradation of the neat $S R$ and nanocomposites was clearly seen when the $T_{50}$ values were compared. This was because $\mathrm{SR}$ is more stable in a nitrogen atmosphere due to the absence of oxygen that induces chain scission but SR usually degrades at higher temperatures [28]. Camino 
and co-workers [28] reported that the neat SR decomposed to cyclic oligomers at temperatures above $400^{\circ} \mathrm{C}$ in nitrogen.

Note that with regard to the neat SR, the $T_{50}$ of the SR/Na ${ }^{+} M M T, S R / C 30 B$ and SR/C20A nanocomposites shifted from $455^{\circ} \mathrm{C}$ (for the neat $\mathrm{SR}$ ) to $506^{\circ} \mathrm{C}, 506^{\circ} \mathrm{C}$ and $521^{\circ} \mathrm{C}$, respectively. An increment of $66^{\circ} \mathrm{C}$ in $T_{50}$ value was observed for the SR/C20A nanocomposite. In addition, when the final residues at $650^{\circ} \mathrm{C}$ were compared, the $\mathrm{SR} / \mathrm{Na}^{+} \mathrm{MMT}$ and SR/C30B nanocomposites showed about $11 \%$ improvement compared with the neat SR. Surprisingly, no such improvement was observed for the SR/C20A nanocomposite where the final residue was similar to that of the neat SR. A possible reason for this behavior may be due to the influence of the organic surfactant in the C20A clay. This will be discussed at a later stage.

Figs. 9(a-c) illustrate the DTG data for the neat SR and nanocomposites from the thermal degradation tests in a nitrogen atmosphere. The neat SR had undergone two degradation stages in nitrogen as suggested by the appearance of two characteristic peaks. In addition, the SR/Na ${ }^{+} \mathrm{MMT}$ (Fig. 9a) and SR/C30B (Fig.9b) nanocomposites exhibited three distinct degradation stages, showing a shoulder and followed by two main stages. The $T_{\max }\left(T_{01}\right.$ and $\left.T_{02}\right)$ of the $S R / \mathrm{Na}^{+} M M T$ and SR/C30B nanocomposites appeared at higher temperatures when compared with the neat SR. This indicated that the presence of $\mathrm{Na}^{+} \mathrm{MMT}$ and $\mathrm{C} 30 \mathrm{~B}$ clays significantly delayed the thermal degradation of the rubber.

On the other hand, the SR/C20A nanocomposite showed a more complex degradation behavior as seen by the appearance of a shoulder and three peaks 
$\left(\mathrm{T}_{01}, \mathrm{~T}_{02}\right.$ and $\left.\mathrm{T}_{03}\right)$ at $400^{\circ} \mathrm{C}$ to $500^{\circ} \mathrm{C}$ and also one distinct characteristic peak at higher temperature (Fig. 9c). Taking into account this observation, the decomposition of the organic surfactant (dimethyl, dihydrogenated tallow, quaternary ammonium), in C20A clay must be considered in understanding the SR/C20A nanocomposite behavior even though the amount of the clay used was only 6 phr. Cervantes-Uc and co-workers [29] reported a complex thermal degradation mechanism for the Cloisite $20 \mathrm{~A}$ clay in comparison to the unmodified Cloisite $\mathrm{Na}^{+} \mathrm{MMT}$ and 30B clays.

Hence, it may be assumed that the complex behavior of the SR/C20A nanocomposite could be attributed to the decomposition of the organic surfactant in the C20A clay as reported in a previous study [29]. In this study, the SR/C20A nanocomposite showed three $\mathrm{T}_{\max }$ values at $439^{\circ} \mathrm{C}, 488^{\circ} \mathrm{C}$ and $557^{\circ} \mathrm{C}$, which corresponded to $0.39 \% /{ }^{\circ} \mathrm{C}, 0.55 \% /{ }^{\circ} \mathrm{C}$ and $0.89 \% /{ }^{\circ} \mathrm{C}$ degradation rates, respectively. The trend showed degradation rate of the SR/C20A nanocomposite accelerating as temperature was raised from 439 to $557^{\circ} \mathrm{C}$ (Table 3). This explained why low yield residue was obtained at $650^{\circ} \mathrm{C}$ for this nanocomposite.

Overall, it showed that the SR/C20A nanocomposite had poor thermal stability in nitrogen when compared to the SR/C30B and SR/Na ${ }^{+} \mathrm{MMT}$ nanocomposites. One might expect that the thermal stability of the SR/C20A nanocomposite containing intercalated clay was better than that of the SR/Na ${ }^{+} \mathrm{MMT}$ nanocomposite with intercalated/exfoliated clay due to the filler morphology. Since the opposite behavior was observed, it was therefore assumed that the organic surfactant in the C20A clay had influenced the thermal stability of the rubber. On the other hand, low interfacial interaction in the 
SR/C20A nanocomposite as reported earlier [18] might have contributed to the poor thermal stability of the rubber.

\section{Thermal oxidative degradation kinetics of the neat $S R$ and SR/C30B nanocomposite}

Referring to the thermal oxidative degradation results discussed in the earlier section (Table 2, Fig. 6), it was observed that the highly exfoliated C30B clay platelets acted as an effective barrier to the diffusion of oxygen into the rubber, hence lowering the mass loss decomposition rate of the SR/C30B nanocomposite. Accordingly, the mechanism of thermal oxidative degradation in the neat $\mathrm{SR}$ and nanocomposite was investigated using the thermal oxidative degradation kinetics analysis. In general, to determine thermal stability of a polymer, measuring activation energy of decomposition is an important kinetic parameter. Activation energy is defined as the minimum amount of energy required for initiating a particular process usually in the context of chemical reactions. According to Maiti and co-workers [30], the total activation energy of degradation of clay-filled rubber nanocomposites was attributed to the activation energy of degradation of rubber and energy to break the polymer-filler interaction.

The activation energies against conversion level during thermal oxidative degradation process of the neat $\mathrm{SR}$ and SR/C30B nanocomposite were determined following the procedure described in ASTM E1641-07 [16]. Firstly, a rapid TGA test of the two rubbers was carried out at $5^{\circ} \mathrm{C} / \mathrm{min}, 10^{\circ} \mathrm{C} / \mathrm{min}$ and $20^{\circ} \mathrm{C} / \mathrm{min}$ heating rates (Figs. $10(a-b))$. As expected, by increasing the heating rate to $20^{\circ} \mathrm{C} / \mathrm{min}$ the weight loss shifted to higher temperatures for both the neat SR (Fig. 10a) and nanocomposite (Fig. 10b). 
This indicated that the chemical reactions causing thermal degradation were temperature dependent as reported previously [28].

According to the standard method [16], the heating rate $\beta$ was transformed to log $\beta$ whereas absolute temperature $(K)$ was converted to $1 / T$. Then, the logarithms of the heating rates $(\beta)$ were plotted against absolute temperature $(1 / T)$ at any given conversion level to yield a straight line. Figs. 11(a-b), exhibit Arrhenius plot of log heating rate $\beta\left({ }^{\circ} \mathrm{C} / \mathrm{min}\right)$ against absolute temperature $1000 / \mathrm{T}(\mathrm{K})$ of a constant conversion data for the neat SR (Fig. 11a) and SR/C30B nanocomposite (Fig. 11b), respectively. By fitting the straight lines to the actual data, the slope $(m)$ of the lines was measured where $m$ was $\Delta(\log \beta) / \Delta(1 / T)$. The $m$ and $\mathrm{b}$ values, where $\mathrm{b}$ was $0.457 / \mathrm{K}$, were placed in Equation 2 to determine the activation energy.

Fig. 12 displays activation energy of the neat SR and SR/C30B nanocomposite during the thermal oxidative decomposition against conversion level in air. It can be seen clearly from the figure that the nanocomposite possessed lower activation energy when compared with the neat SR at conversion levels less than approximately $10 \%$. However, at the highest conversion level, i.e. $20 \%$, the activation energy of the nanocomposite was $56 \%$ higher which indicated a much better thermal stability.

As this study has shown, exfoliated $\mathrm{C} 30 \mathrm{~B}$ clay had major advantages for the thermal stability and heat resistance of the rubber. Probably, the most interesting finding of this study was the fact that the clay morphology did modify the thermal properties of the rubber for the better. This was in addition to the good mechanical properties reported for the aged nanocomposites containing exfoliated C30B clay. 


\section{CONCLUSIONS}

From this study, it can be concluded that

- Addition of the montmorillonite clay enhanced the heat resistance of the rubber as reflected by higher retention strength of the nanocomposites when compared with the neat SR. The presence of exfoliated C30B clay protected the rubber against chain scission and direct oxidation, hence significantly delaying the degradation process. In addition, the FTIR results showed that some crosslinks were formed in the neat SR and SR/C30B nanocomposite with increasing the ageing time to $24 \mathrm{~h}$ at $200^{\circ} \mathrm{C}$.

- The thermal stability in air was strongly dependent on the clay morphology which was found to increase in the following order: highly intercalated/exfoliated SR/Na ${ }^{+} \mathrm{MMT}<$ highly intercalated SR/C20A < highly exfoliated SR/C30B. Moreover, the exfoliated C30B clay platelets prevented oxygen from diffusing into the rubber during degradation and this increased the thermal stability of the nanocomposite. Furthermore, the SR/C30B nanocomposite containing exfoliated clay had lower thermal degradation rate, better thermal decomposition stability as well as higher activation energy in comparison to the neat SR.

- Exact effect of the clay morphology on the thermal degradation of the rubber in nitrogen atmosphere was not clear. However, the organic modifier in the C20A clay might have played a role in influencing the thermal stability of the nanocomposite in the inert atmosphere. 


\section{ACKNOWLEDGEMENTS}

We are grateful to the Malaysian Rubber Board for funding this project. We also thank the Loughborough Materials Characterization Centre and Tun Abdul Razak Research Centre (TARRC), Hertfordshire, UK for their technical assistance. 


\section{REFERENCES}

1. Voulomenou, A. and Tarantili, P.A., J. Appl. Polym Sci., 2010, 118, 2521-2529

2. Burnside, S. D. and Giannelis, E. P. J. Polym. Sci. B Polym Phys., 2000, 38, 1595-1604

3. Kaneko, M. L. Q. A and Yoshida, I. V. P, J. Appl. Polym Sci., 2008, 108, 25872596.

4. Vaulot, C.; Ziegler, P. and Haidar, B., Polymer, 2011, 52, 700-707

5. Jia, C.; Zhang, L.-Q.; Zhang, H. and Lu, Y.-L. Polym Compos, 2011, 32,12451253.

6. Schmidt, D. F.; Clément, F and Giannelis,D E. Adv. Funct Mater., 2006, 16, 417425.

7. Kaneko, M. L. Q. A.; Romero, R. B.; Gonçalves, M.C. and Yoshida, I. V. P., Eur Polym J., 2010, 46, 881-890.

8. Wang, J.; Chen, Y and Jin, Q., Macromol Chem Phys., 2005, 206, 2512-2520.

9. Lewicki J. P.; Liggat, J. J.; Pethrick, R. A.; Patel, M. and Rhoney, I., Polym Degrad Stab., 2008, 93 (1), $158-168$.

10.Kong, Q.; Hu, Y.; Song, L.; Wang, Y.; Chen, Z. and Fan, W. Polym Adv Technol., 2006, 17, 463-467.

11. Jincheng, W. and Wenli, H. J Appl Polym Sci., 2013, 129, 1852-1860.

12. Lewicki, J. P.; Liggat, J. J. and Patel, M. Polym Degrad Stab., 2009, 94(9), 15481557 
13. Stephen, R. and Thomas, S. Rubber nanocomposites: preparation, properties and applications, John Wiley \& Sons, Inc. New Jersey , 2010, Chapter 20.

14. Ansarifar, A. and Lim, B. Y. Rubber Res., 2006, 9(3), 140-158.

15. British Standards Institution. Method for determination of tensile stress-strain properties: BS 903-A19:Part A2: BSI: London, UK, 1995.

16. American Standard Test Method. Method for Decomposition Kinetics by Thermogravimetry; ASTM E1641-07: ANSI, New York, US, 2012.

17.Flynn, J.H. and.Wall, L.A., Polymer letters, 1966, 4 (5), 323-328.

18. Nik Ismail N. I.; Ansarifar, A. and Song, M., 2013, Polym Eng Sci., 53, 2603-2614.

19. Paul, D. R. and Robeson, L. M., Polymer, 2008, 49 (15), 3187-3204.

20. Roy, N. and Bhowmick. A. K. Polymer, 2010, 51, 5172-5185.

21. Bruden, G., J. Ind. Textiles, 1998, 27, 294-308.

22. Thomas, D. K. Polymer, 1964, 5, 463-470.

23. Tomer, N. S.; Delor-Jestin, F.; Frezet, L.; Lacoste, J. Open J Organ Polym Mater 2012, 2, 13.

24.Pielichowski, K. and Njuguna J., Thermal degradation of polymeric materials, Rapra Technology, Shropshire, UK, 2005, Chapter 8.

25. Choudhury, A.; Bhowmick, A. K. and Soddemann, M., Polym Degrad Stab., 2010, 95 (12), 2555-2562

26. Chaudhry, A. N. and Billingham, N. C., Polym Degrad Stab., 2001, 73 (3), 505510. 
27.Pehlivan-Davis, S.; Clarke, J., and Armour, S., J Appl Polym Sci., 2013, 129 (3), $1446-1454$.

28. Camino, G.; Lomakin, S. and Lazzari, M. Polymer, 2001, 42(6), 2395-2402.

29. Cervantes-Uc, J. M.; Cauich-Rodríguez, J. V.; Vázquez-Torres, H.; Garfias-

Mesías, L. F. and. Paul, D. R., Thermochim. Acta, 2007, 457, 92-102.

30. Maiti, M.; Mitra, S. and. Bhowmick, A. K. Polym Degrad Stab., 2008, 93(1), 188200. 
Table I. Tensile Strength, Young's Modulus and Elongation at Break of the Unaged and Aged Neat SR and SR/MMT Nanocomposites

\begin{tabular}{|c|c|c|c|c|}
\hline Aging time $(\mathrm{h})$ & Neat SR & SR/Na1MMT & $\mathrm{SR} / \mathrm{C} 30 \mathrm{~B}$ & $\mathrm{SR} / \mathrm{C} 20 \mathrm{~A}$ \\
\hline \multicolumn{5}{|c|}{ Tensile strength ( $\mathrm{MPa}$ ) } \\
\hline 0 & 0.4060 .03 & 0.6860 .03 & 0.5460 .02 & 0.5260 .01 \\
\hline 10 & 0.2660 .03 & 0.5260 .03 & 0.4260 .02 & 0.4260 .01 \\
\hline 20 & 0.2360 .02 & 0.4560 .01 & 0.4260 .02 & 0.3860 .03 \\
\hline 24 & 0.1960 .01 & 0.4660 .01 & 0.4060 .03 & 0.4060 .03 \\
\hline 30 & 0.1860 .02 & 0.4060 .01 & 0.3260 .01 & 0.3760 .01 \\
\hline \multicolumn{5}{|c|}{ Young's modulus } \\
\hline 0 & 0.3060 .01 & 0.3960 .01 & 0.3560 .01 & 0.3560 .02 \\
\hline 10 & 0.1660 .01 & 0.2560 .01 & 0.2360 .01 & 0.2160 .01 \\
\hline 20 & 0.1560 .01 & 0.2560 .01 & 0.2160 .01 & 0.2060 .01 \\
\hline 24 & 0.1760 .01 & 0.3660 .01 & 0.3260 .01 & 0.2160 .01 \\
\hline 30 & 0.1660 .01 & 0.2960 .01 & 0.2560 .01 & 0.2260 .04 \\
\hline \multicolumn{5}{|c|}{ Elongation at break (\%) } \\
\hline 0 & 639669 & 756629 & 797639 & 910672 \\
\hline 10 & 6586118 & 863637 & 867631 & 968673 \\
\hline 20 & 639673 & 688637 & 969644 & 1009641 \\
\hline 24 & 488642 & 477611 & 571635 & 1006663 \\
\hline 30 & 463633 & 511627 & 530635 & 640664 \\
\hline
\end{tabular}


Table II. Results from the TGA Tests on the Thermal Oxidative Degradation of the Neat SR and SR/MMT Nanocomposites in Air

\begin{tabular}{lllllll} 
& $T_{\text {onset }}$ & $T_{10}$ & $T_{50}$ & Final residue & $\begin{array}{l}\text { Temperature peak } \\
\text { of degradation, } \\
T_{\max }\left({ }^{\circ} \mathrm{C}\right)\end{array}$ & $\begin{array}{l}\text { Peak height } \\
\text { at } T_{\max }\left(\% /{ }^{\circ} \mathrm{C}\right) \\
T_{01}, T_{02}\end{array}$ \\
\hline Neat SR & $\left({ }^{\circ} \mathrm{C}\right)$ & $\left({ }^{\circ} \mathrm{C}\right)$ & $\left({ }^{\circ} \mathrm{C}\right)$ & at $650^{\circ} \mathrm{C}$ & 356,406 & $1.59,0.58$ \\
$\mathrm{SR} / \mathrm{Na}{ }^{1} \mathrm{MMT}$ & 332 & 345 & 396 & 22.3 & 390,468 & $1.35,0.53$ \\
$\mathrm{SR} / \mathrm{C} 30 \mathrm{~B}$ & 340 & 367 & 478 & 30.5 & 385.411 & $0.60,0.78$ \\
\hline $\mathrm{SR} / \mathrm{C} 20 \mathrm{~A}$ & 340 & 375 & 495 & 42.0 & 395,442 & $0.65,0.60$ \\
\hline
\end{tabular}


Table III. Results from the TGA Tests on the Thermal Non-Oxidative Degradation of the Neat SR and SR/MMT Nanocomposites in a Nitrogen Atmosphere

\begin{tabular}{|c|c|c|c|c|c|c|}
\hline & & & & $\begin{array}{l}\text { Final residue } \\
\text { at } 650^{\circ} \mathrm{C}\end{array}$ & $\begin{array}{l}\text { Temperature peak } \\
\text { of degradation, } \\
T_{\max }\left({ }^{\circ} \mathrm{C}\right) \\
T_{01}, T_{02} \text {, and } T_{03}\end{array}$ & $\begin{array}{l}\text { Peak height } \\
\text { at } T_{\max }\left(\% /{ }^{\circ} \mathrm{C}\right) \\
T_{01}, T_{02} \text {, and } T_{03}\end{array}$ \\
\hline Neat SR & 370 & 399 & 455 & 21.1 & 412,474 & $1.21,0.53$ \\
\hline $\mathrm{SR} / \mathrm{Na}^{1} \mathrm{MMT}$ & 378 & 405 & 506 & 23.5 & 447,509 & $1.57,0.52$ \\
\hline SR/C30B & 379 & 411 & 506 & 23.1 & 445,514 & $0.93,0.73$ \\
\hline SR/C20A & 368 & 397 & 521 & 21.1 & $439,488,557$ & $0.39,0.55,0.89$ \\
\hline
\end{tabular}




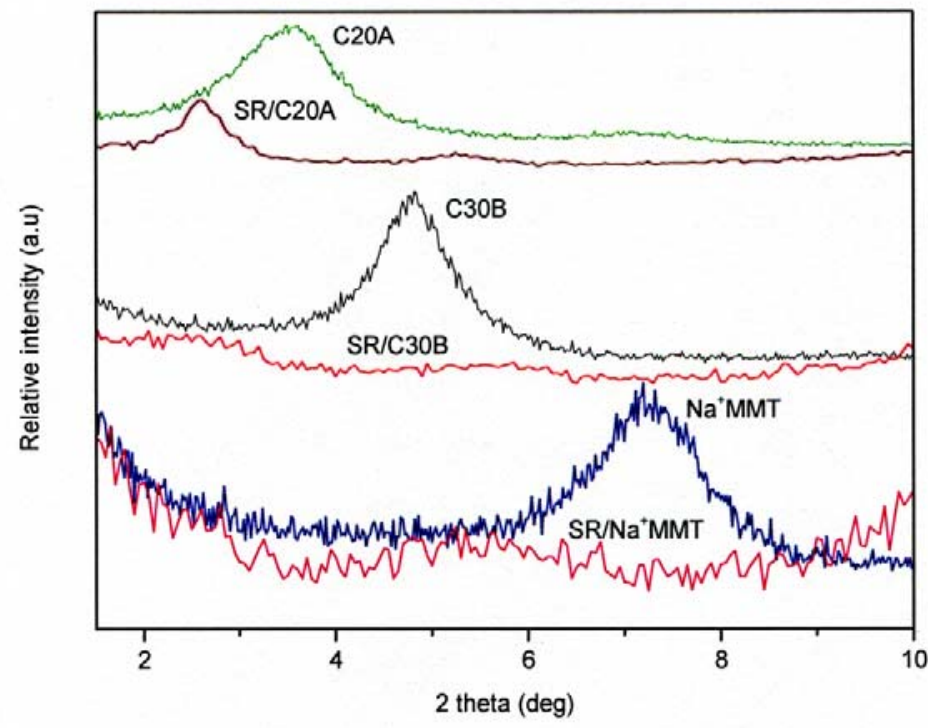

Figure 1 - XRD spectra of the MMT clay and SR/MMT nanocomposites. 


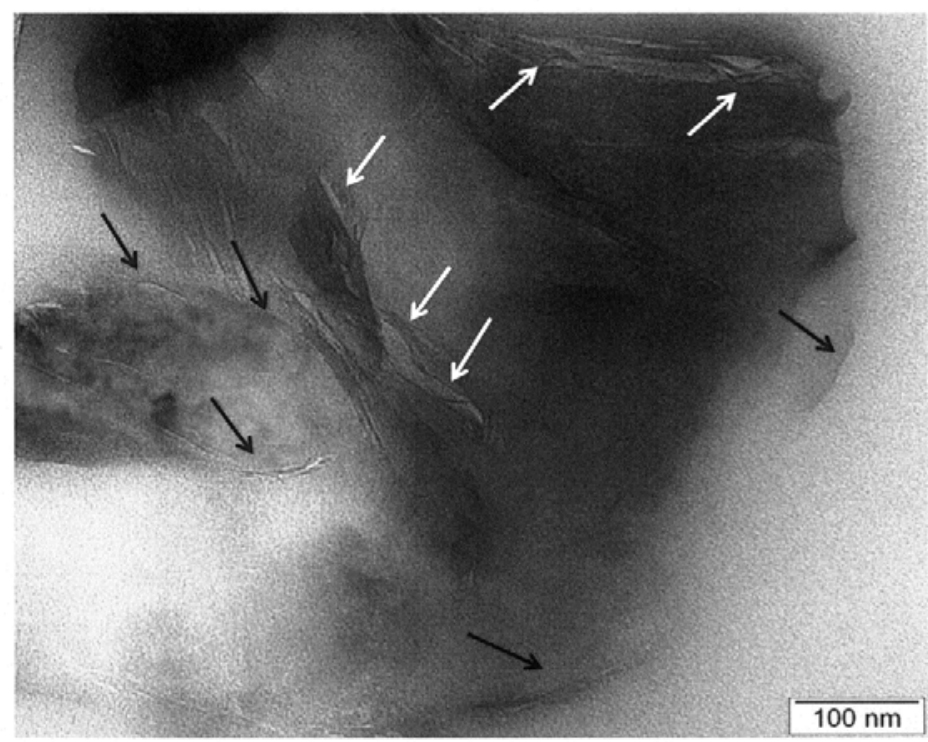

2a - TEM image for the SR/Na ${ }^{+} M M T$ nanocomposite showing dispersion of the MMT particles in the rubber matrix. 


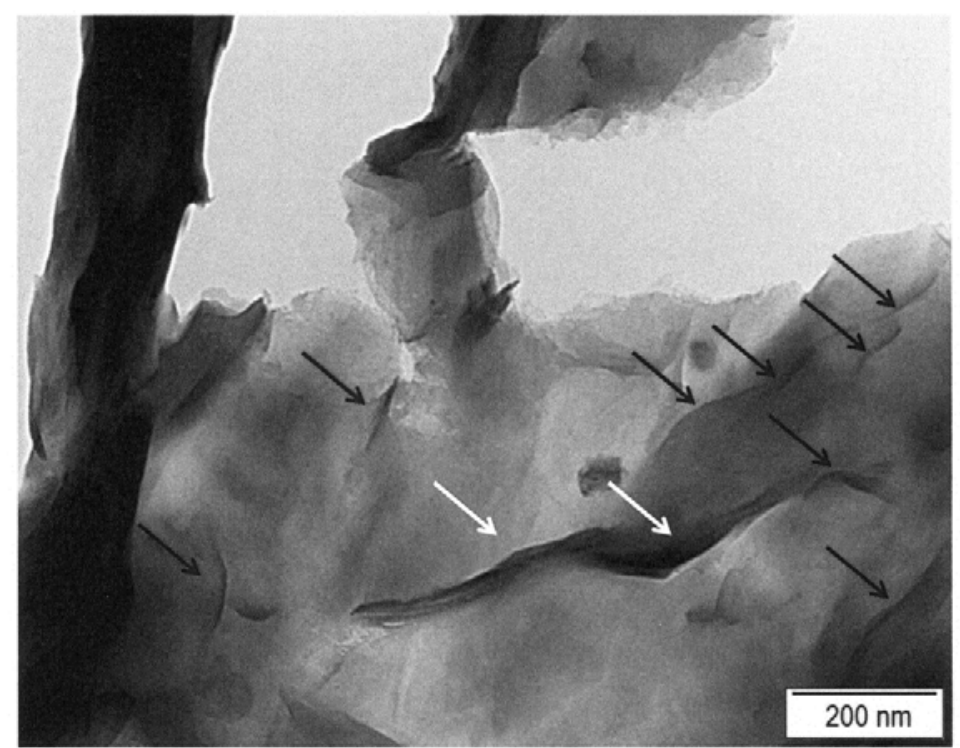

$2 b$ - TEM image for the SR/C30B nanocomposite showing dispersion of the MMT particles in the rubber matrix. 


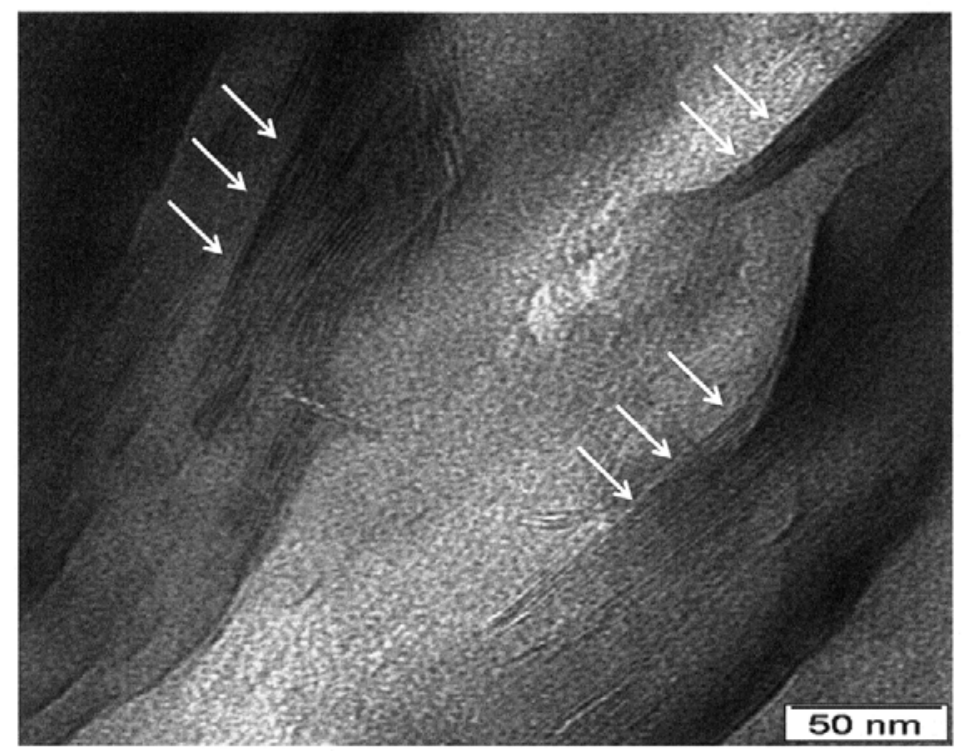

2c - TEM image for the SR/C20A nanocomposite showing dispersion of the MMT particles in the rubber matrix. 

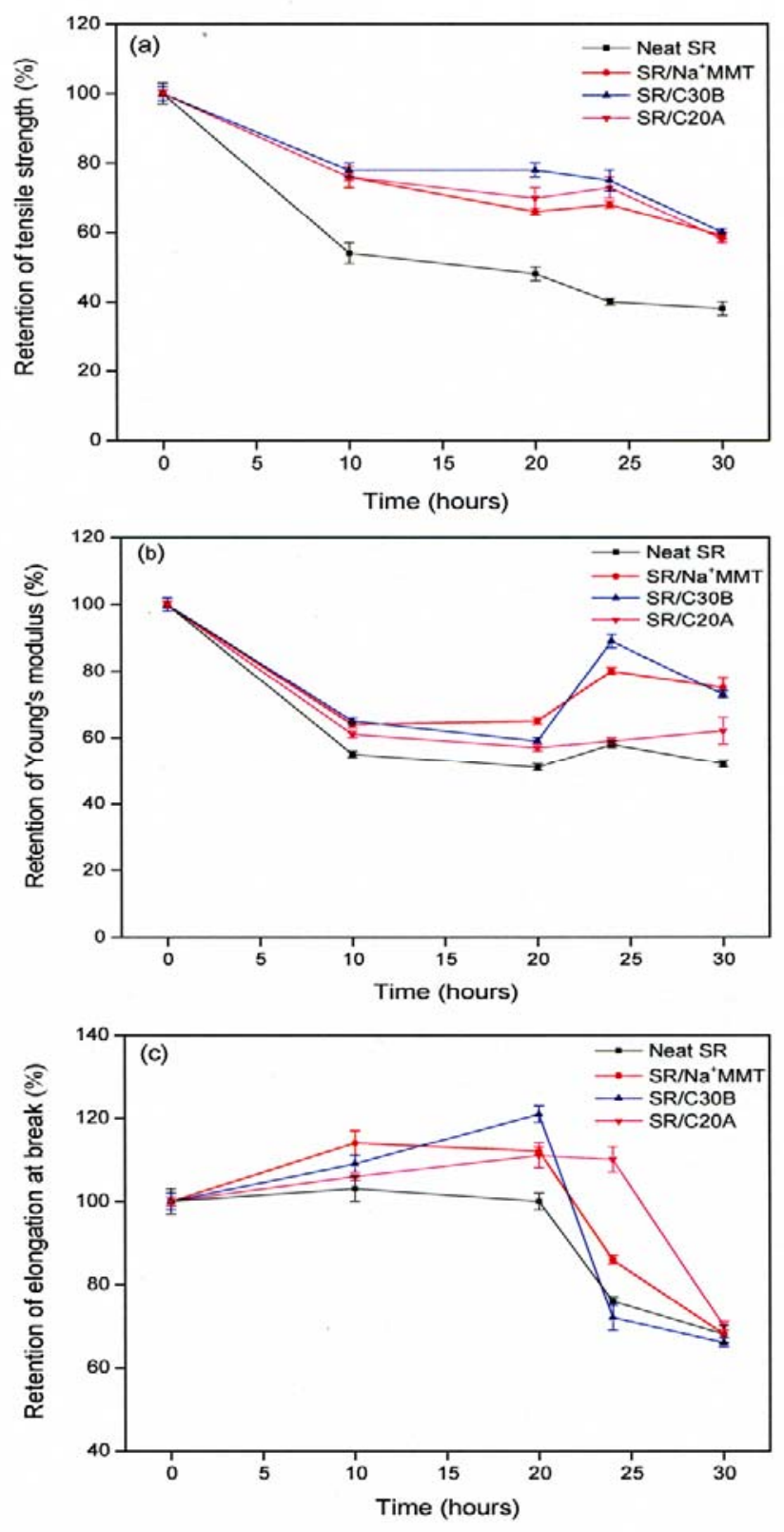

3(a-c): Percent retention of (a) tensile strength (b) young's modulus (c) elongation at break for the neat SR and SR/MMT nanocomposites as a function of aging time at $200^{\circ} \mathrm{C}$. 

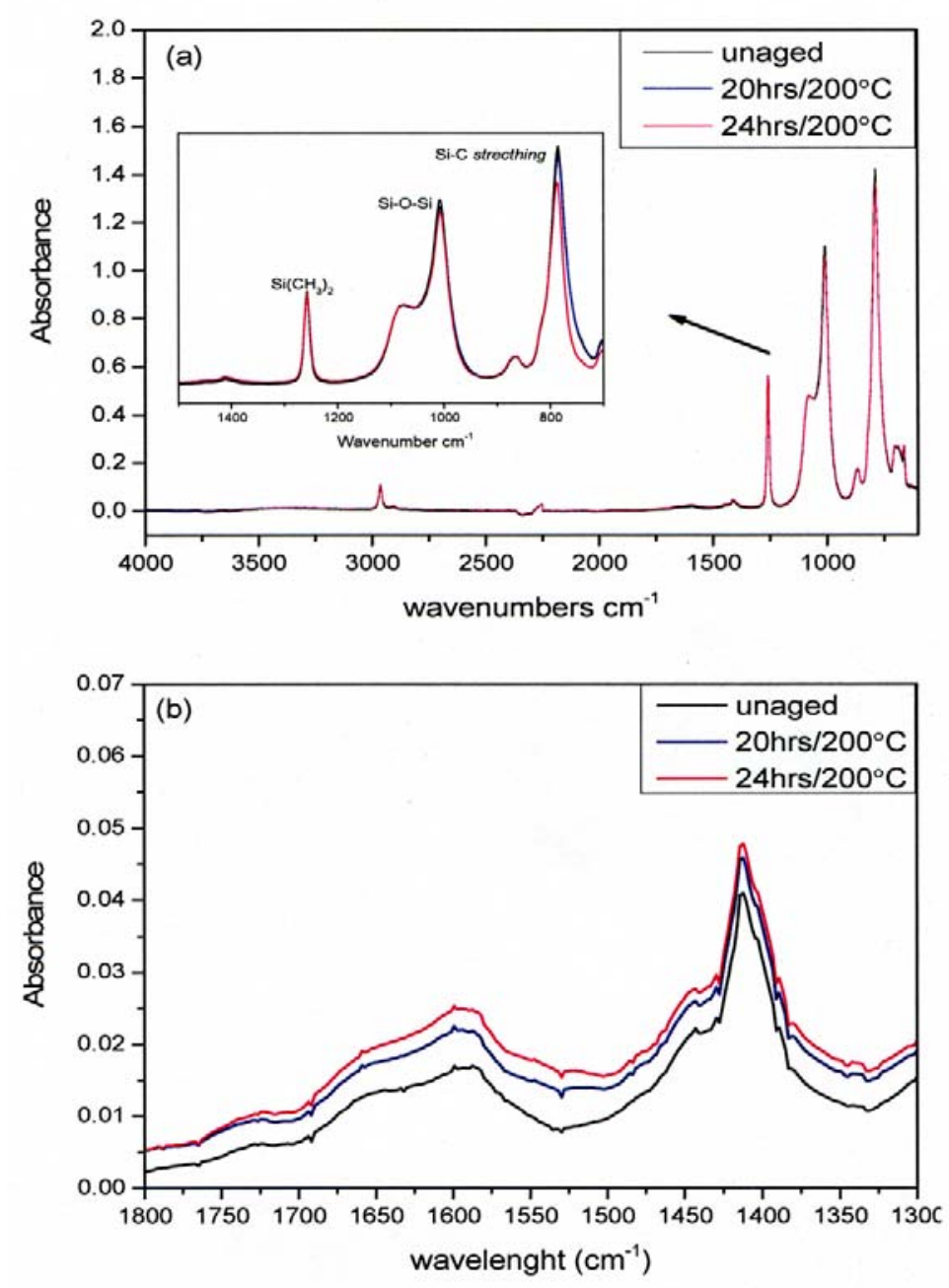

4(a-b): ATR-FTIR spectra of (a) cured neat SR (b) crosslinking network in the neat SR before and after aging at $200^{\circ} \mathrm{C}$ for $20 \mathrm{~h}$ and $24 \mathrm{~h}$. 

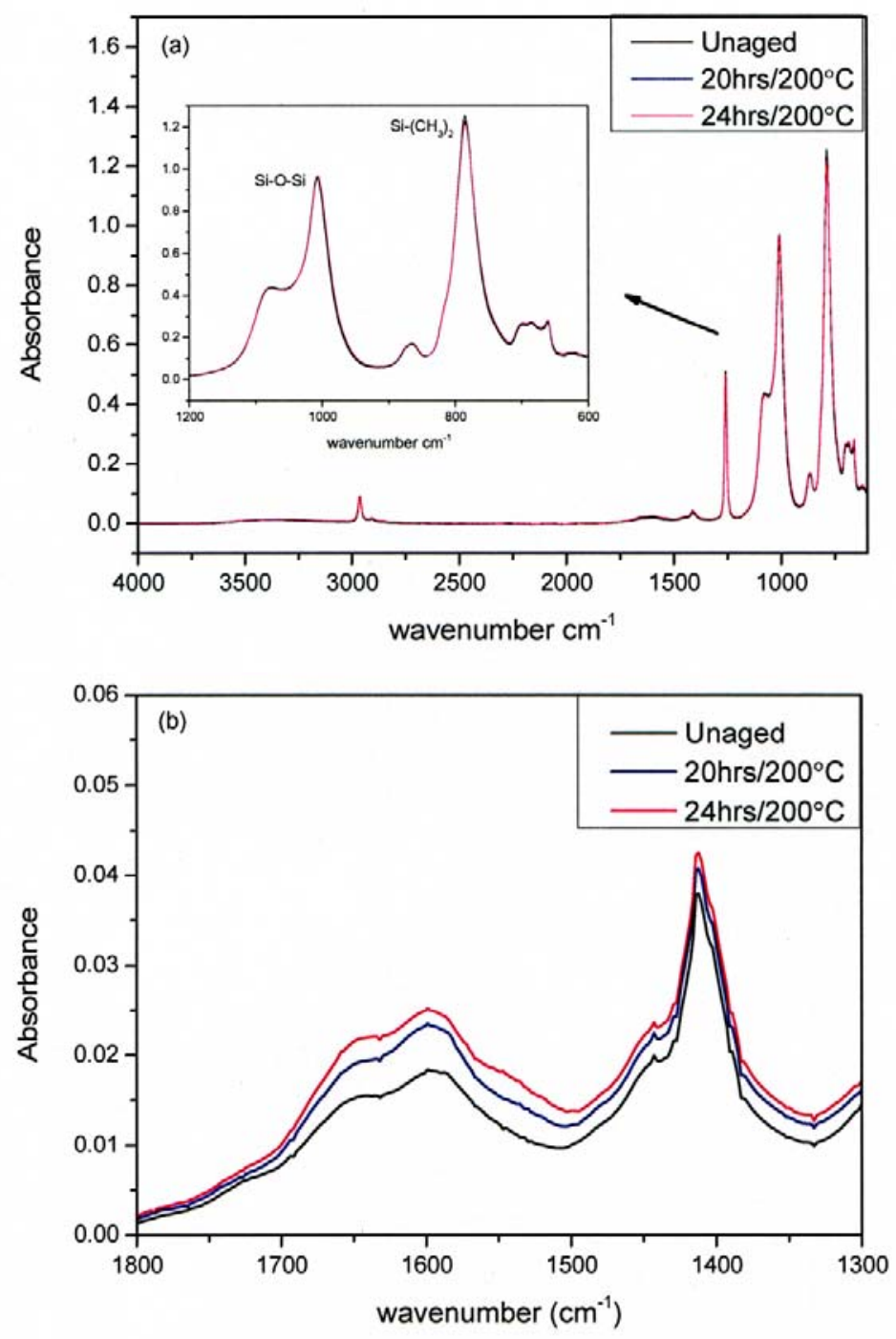

5(a-b): ATR-FTIR spectra of (a) SR/C30B nanocomposite and (b) crosslinking network in the SR/C30B nanocomposites before and after aging at $200^{\circ} \mathrm{C}$ for 20 and $24 \mathrm{~h}$. 


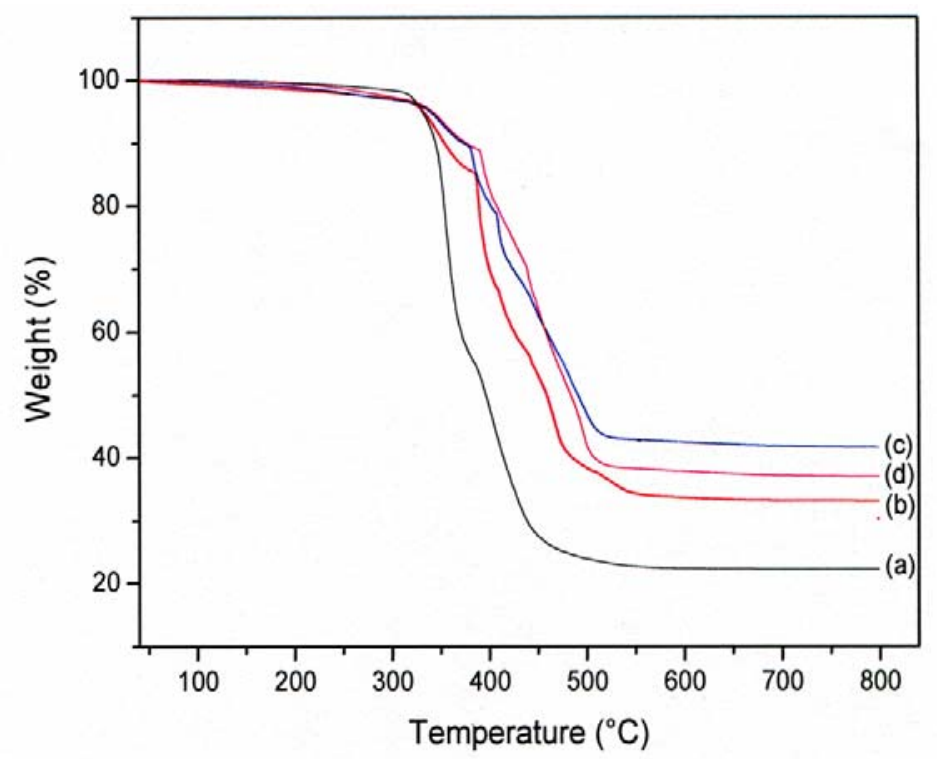

6 - TGA curves of (a) neat SR (b) SR/Na ${ }^{+} M M T$ (c) SR/C30B and (d) SR/C20A nanocomposites in air. 

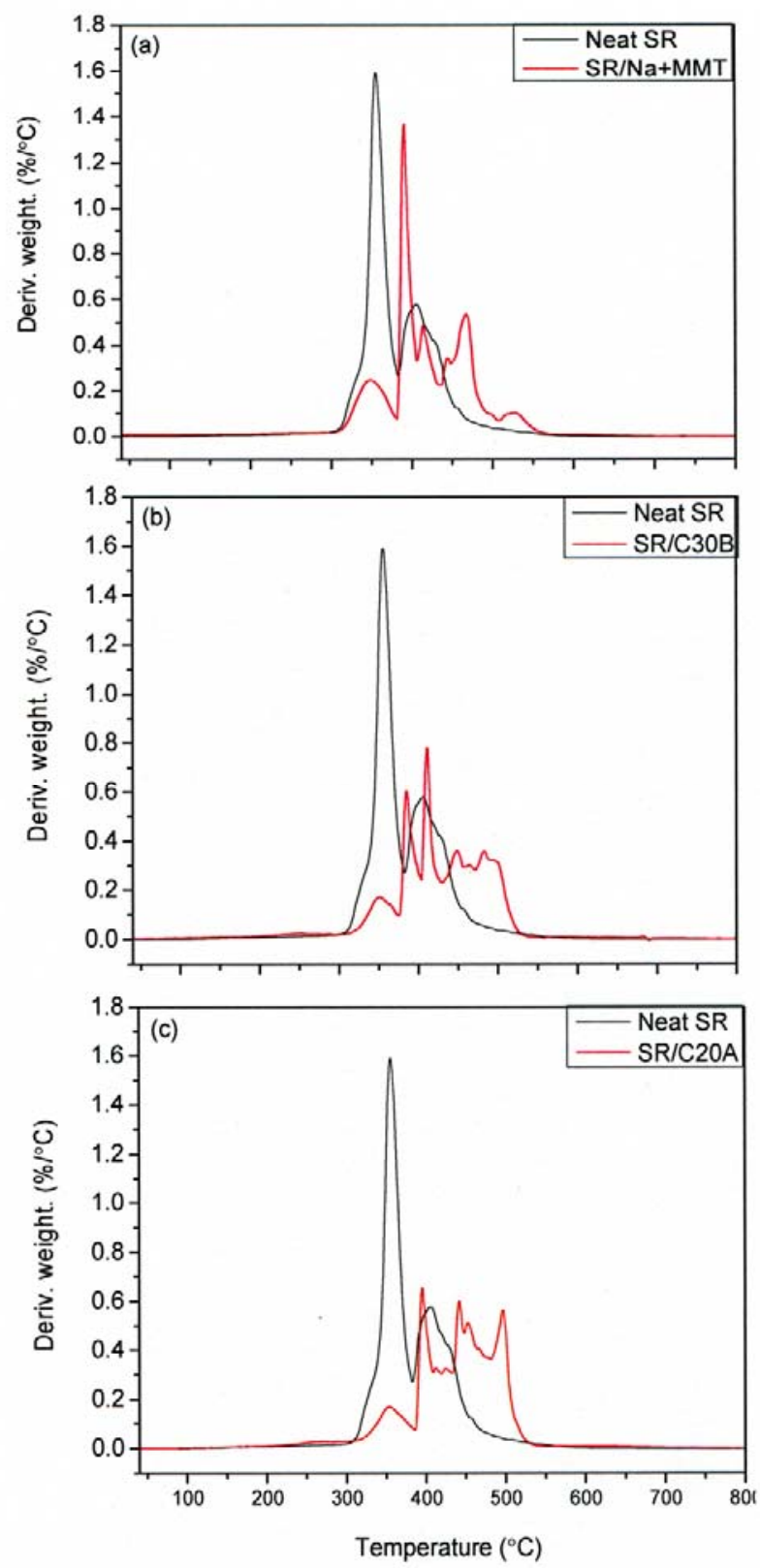

7 (a-c): DTG plots of the neat SR and SR/MMT nanocomposites in air. 


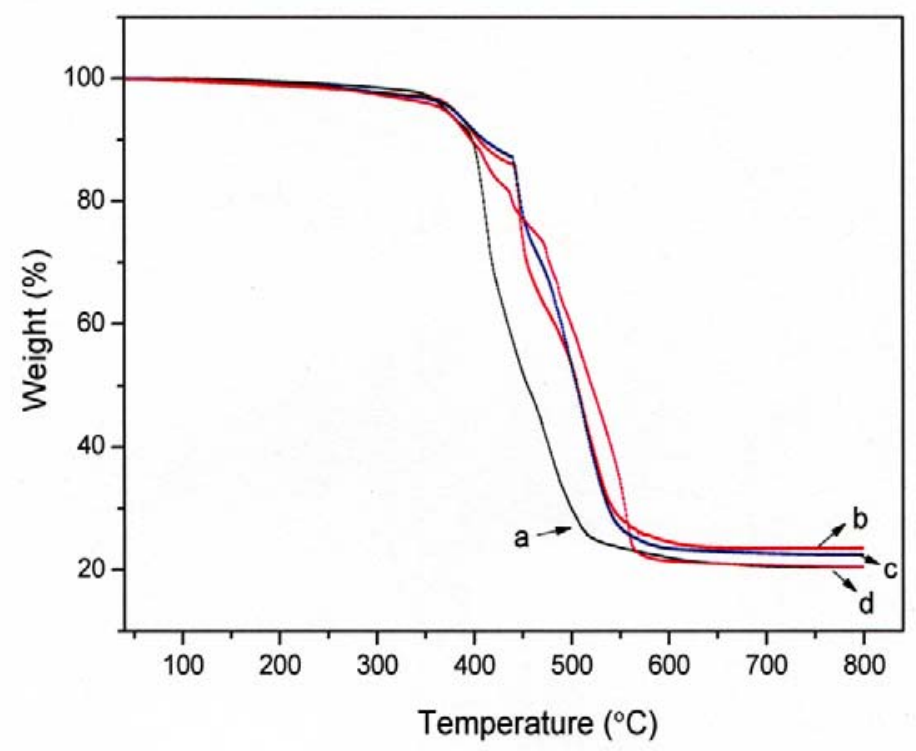

8 - TGA curves of (a) neat SR (b) SR/Na ${ }^{+} M M T$ (c) SR/C30B and (d) SR/C20A nanocomposites in a nitrogen atmosphere. 

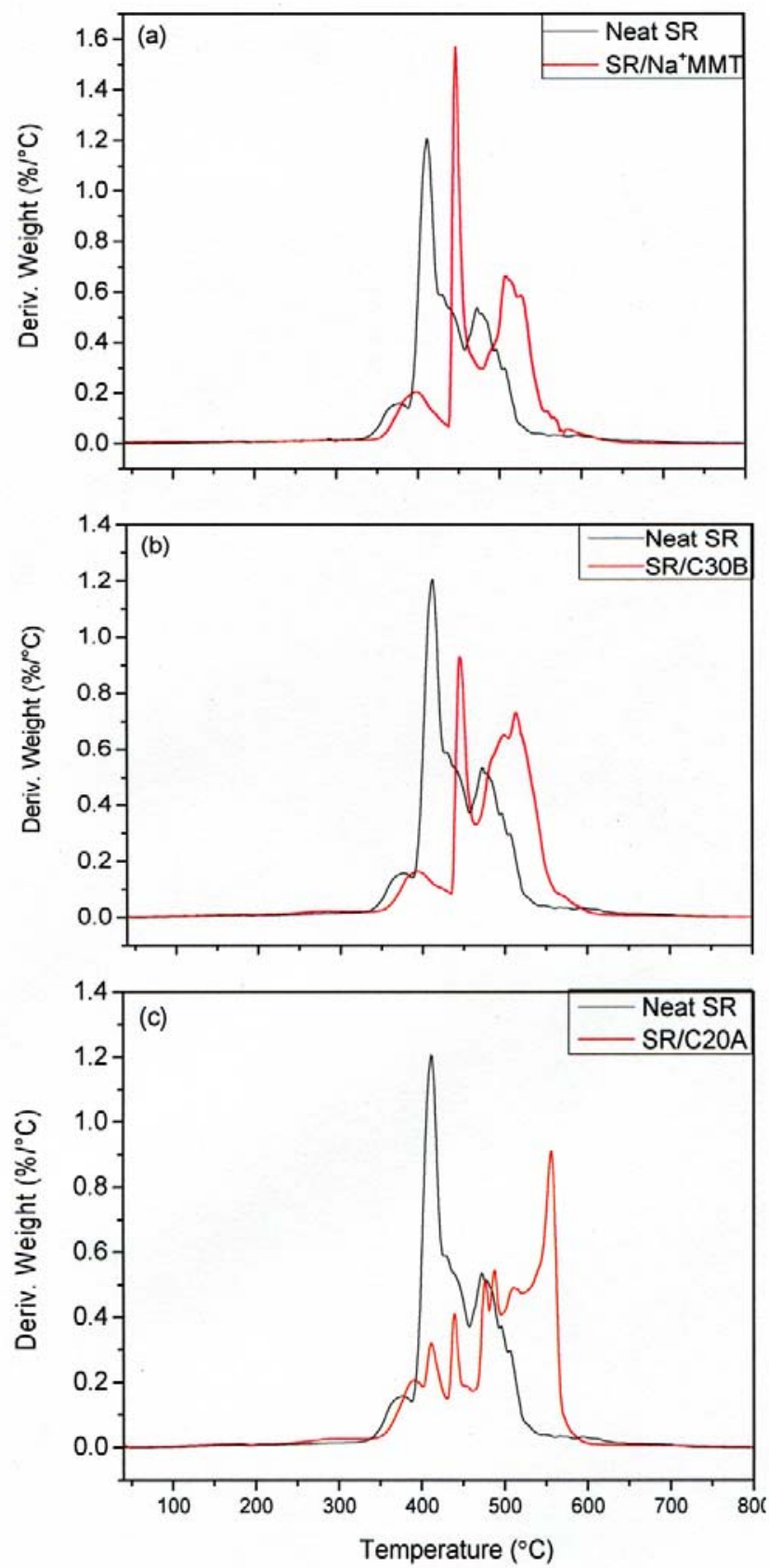

9 (a-c): DTG plots of the neat SR and SR/MMT nanocomposites in a nitrogen atmosphere. 

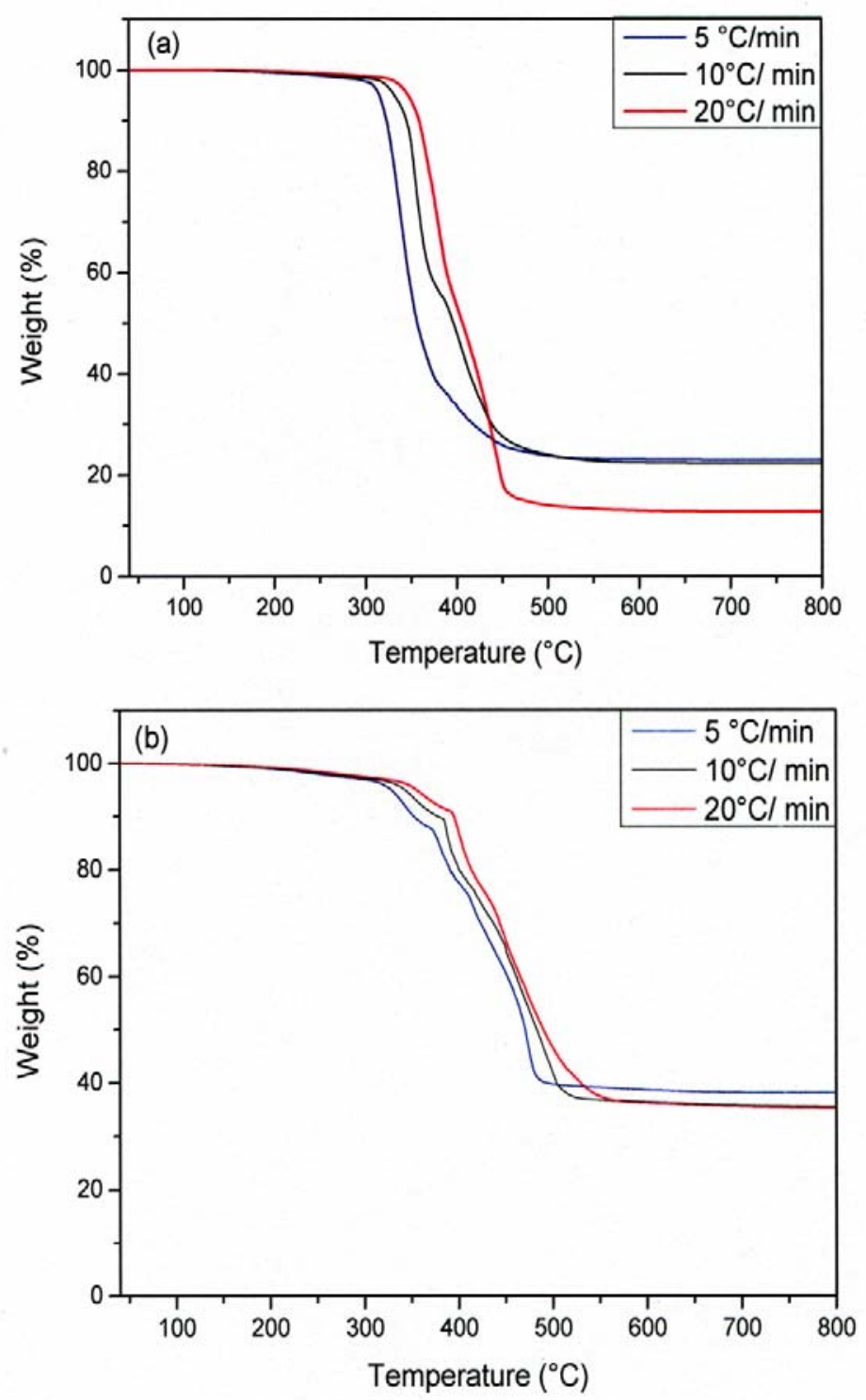

10(a-b): TGA curves of (a) neat SR and (b) SR/C30B at $5^{\circ} \mathrm{C} / \mathrm{min}, 10^{\circ} \mathrm{C} / \mathrm{min}$ and $20^{\circ} \mathrm{C} /$ min heating rates. 

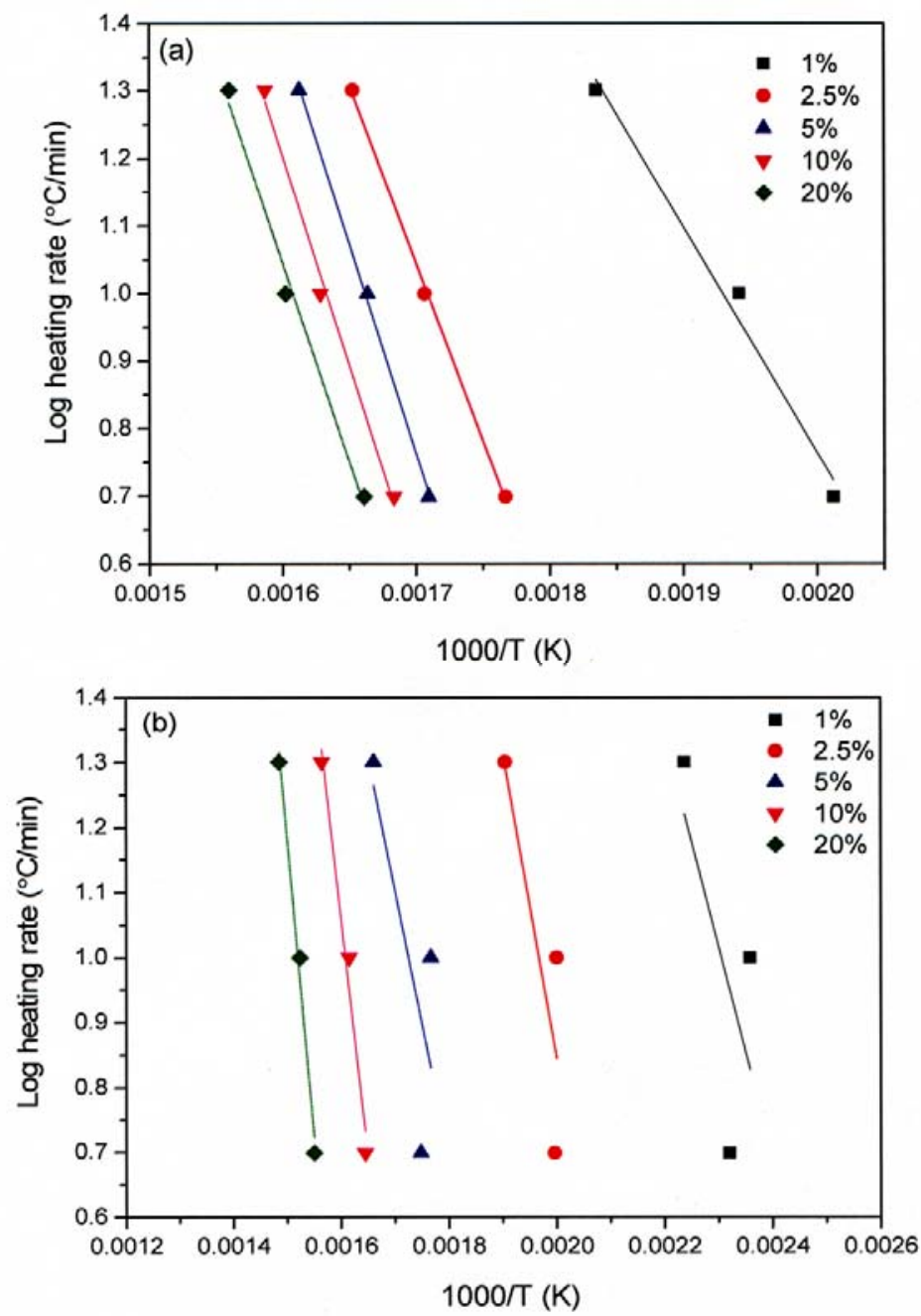

11(a-b): Arrhenius plots of log heating rate against temperature of constant conversion data for a) neat SR and b) SR/C30B nanocomposite. 


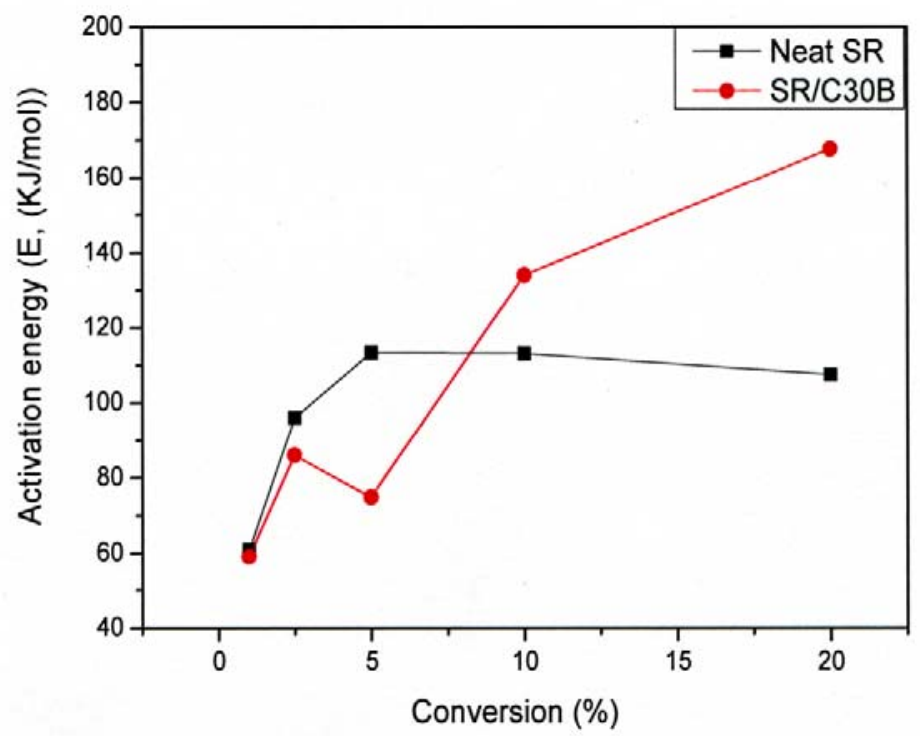

12 -Activation energy of the neat SR and SR/C30B nanocomposite during decomposition process against conversion rate in air. 